\title{
LA VISIÓN INFINITA EN EL ALEPH DE JORGE LUIS BORGES Y EN DE VISIONE DEI DE NICOLÁS DE CUSA
}

\author{
Maja ŠABEC \\ Universidad de Ljubljana
}

\begin{abstract}
Résumé (Fr): Jorge Luis Borges a intégré dans son œuvre une multitude de défis métaphysiques, notamment son obsession pour le concept de l'infini, présent dans presque tous ses textes sous la forme de bibliothèques, déserts, chemins fourchus, etc. L'infini est pour l'auteur argentin une dimension qui dissout la réalité ou la transforme en une autre réalité, celle des interminables multiplications, réflexions, rêves et simulacres. Dans son conte emblématique El Aleph les spéculations sur l'infini se concentrent sur la possibilité pour un être humain d'atteindre la compréhension totale de l' « inconcevable univers »; ainsi, cette connaissance est représentée par la métaphore de la visualisation simultanée de tous points de l'univers à tout moment, entrelacés dans une petite sphère. C'est à partir de ces deux points relatifs, d'un côté, à la connaissance humaine et, de l'autre, à sa représentation comme métaphore que nous explorons les possibles corrélations entre l'approche borgésienne et la pensée de Nicolas de Cues, théologien et philosophe du $X^{\mathrm{e}}$ siècle qui - à partir de l'idée selon laquelle Dieu est infini et parfait - examine dans son traité De Visione Dei la différence entre la capacité infinie de la vision de Dieu et les limitations de la vision humaine, d'où l'incapacité de l'être humain à atteindre la plénitude de la connaissance.
\end{abstract}

\begin{abstract}
En): Jorge Luis Borges integrated in his work a large amount of metaphysical challenges, especially his obsession with the concept of infinity which is present in almost all of his texts in the form of bookshelves, deserts, branched roads etc. Infinity is, for this Argentinian writer, a dimension which dissolves the reality or which it transforms into another reality, one of neverending multiplications, reflexions, dreams and illusions. In his emblematic short story El Aleph, the thoughts concerning infinity concentrate on the possibility of a human to achieve a complete understanding of the inconceivable universe; thus this understanding is represented by the metaphor of simultaneous visualisation of all the point of the universe in all the moments interlaced in a small sphere. It is on the basis of these two relative points, the human knowledge on the one hand and its metaphoric representation on the other hand, that we explore the possible correlations between Borges's approach and the thinking of Nicolas de Cues, a 15th century theologist and philosopher who on the basis of his idea, according to which God is infinite and perfect, considers in his treatise De Visione Dei, the difference between God's infinite capacity of sight and the limitations of the human vision which is the cause of the human incapacity to achieve complete knowledge.
\end{abstract}

Mots-clés (Fr) : Borges; El Aleph; Nicolas de Cues; De visione Dei; infini; univers; connaissance;

Key words (En): Borges, El Aleph, Nicolas de Cues, De visione Dei, infinity, univers, knowledge

Palabras clave (Es): Borges; El Aleph; Nicolás de Cusa; De visione Dei; infinito; universo; conocimiento;

\section{Introducción}

Jorge Luis Borges ha logrado integrar en su obra una multitud de desafíos metafísicos, entre los que destaca su obsesión con el concepto del infinito, cuya presencia nos hace sentir en forma de bibliotecas, desiertos, senderos bifurcados etc. en casi todos sus textos. El infinito es para el autor argentino una dimensión 
que hace disolver la realidad o transformarla en otra realidad, la de multiplicaciones interminables, reflejos, sueños y simulacros. El autor, a su vez, juega en sus textos con una infinita variedad de planteamientos filosóficos y procedimientos literarios para crear estas realidades, unas veces apenas refiriéndose a ellas, otras cimentándolas con complejas argumentaciones.

En su cuento antológico El Aleph las especulaciones sobre el infinito se centran en la eventualidad de que un ser común alcance el poder de la comprensión total del « inconcebible universo », y este conocimiento se representa mediante la metáfora de la visión simultánea de todos los puntos del universo en todos los tiempos - pasado, presente y futuro - entreverados en un pequeño globo. Es en estos dos puntos referentes al conocimiento humano por un lado, y a la visión como metáfora de aquel por el otro, donde hemos explorado las posibles vinculaciones entre el planteamiento borgeano y el pensamiento de Nicolás de Cusa, teólogo y filósofo del siglo XV que partiendo de la premisa de que Dios es infinito (y perfecto), examina en su tratado De visione Dei la diferencia entre la infinita capacidad de la visión divina y las limitaciones de la visión humana y, por consiguiente, la incapacidad del ser humano de alcanzar la plenitud del conocimiento.

Borges, como es bien sabido, hace alarde de su extraordinaria erudición al introducir en gran parte de sus textos referencias y autoridades de muy diversa índole - entre otros filósofos, científicos, matemáticos tanto de la tradición oriental como de la occidental, desde la antigüedad hasta su tiempo - para legitimar sus más osadas reflexiones. Entre los postulados sobre los que construye su visión del universo se encuentran también los del cardenal alemán: aunque su nombre sea mencionado nada más que en dos ocasiones - en el ensayo Avatares de la tortuga y en el cuento Abenjacán el Bojari, muerto en su laberinto - es cierto que su pensamiento, adquirido por Borges sea en la Patrología de Migne sea a través de sus innumerables lecturas de historias del pensamiento medieval, está presente de manera implícita en numerosos textos del erudito argentino. Es el caso, particularmente, del ensayo La esfera de Pascal (cf. DANVERS, 2006: 290-291; PALMA, 2007), y de varios relatos asociados a las paradojas cosmológicas del infinito, como lo demuestra, por ejemplo, MAGNAVACCA $(2005,2007)$ basándose en el tema de La bibiloteca de babel. La mera ausencia del nombre de Cusa en El Aleph, por lo tanto, carece de relevancia en nuestro propósito de emprender una « lectura cusana ».

\section{Nicolás de Cusa, De visione Dei}

Nicolaus Cusanus (1401-1464), figura clave en la transición del pensamiento medieval al del Renacimiento, escribió más de treinta tratados de temas filosóficos, teológicos, matemáticos y astronómicos que confirman su perfil de humanista y científico polifacético. El texto más relevante para el tema que nos ocupa es De visione Dei, ya que ilustra perfectamente la relación entre los dos polos opuestos que trabaja el cuento de Borges, es decir, entre conocimiento infinito y finito. 
El eje alrededor del que se construye este tratado, que consta de veinticinco capítulos, es la diferencia entre la visión humana, y la visión divina ${ }^{1}$. Cusa lo escribió como respuesta a la solicitud de los monjes de Tegernsee para que fueran introducidos en la teología mística. Junto con el texto, el autor les mandó también un cuadro con el retrato de la faz de Jesucristo visto de frente. Se trata de uno de aquellos iconos en los que los ojos del sujeto parecen estar mirando directamente al espectador y aunque éste se mueva a un lado u otro del cuadro la mirada del cuadro le va siguiendo. Hay muchas representaciones de Cristo en las que los pintores emplean esta ilusión óptica que hace que el espectador, al mirar el cuadro, sea a la vez objeto mirado, observado, escrutado. Cusa había visto, según cuenta en el Prefacio al tratado, tales representaciones en Nuremberg, Bruselas, Coblenza y Bresannone. Este icono le sirve literalmente como ilustración y como punto de partida para el ejercicio del acercamiento al enigma de la divinidad. Así les ordena a los monjes:

Colocad ese icono en cualquier lugar, por ejemplo en la pared que está al norte, poneos alrededor, hermanos, a poca distancia de él, y observadlo; cada uno de vosotros, desde cualquier lugar que lo mire, comprobará que el icono parece que le mira solamente a él (CuSA, 2009: 65)².

La homología de la metafísica de Cusa y de la pintura ilusionista no es, por supuesto, técnica, sino conceptual (VESEL, 1996). Al apoyarse en esta plasmación pictórica el filósofo transmite la idea de la omnipresencia de Dios que «tiene grandísimo cuidado tanto de la creatura más pequeña como de la más grande y de todo el universo » (Prefacio, 66), cuya visión es, por lo tanto, « a la vez universal y particular», apta para contemplar «simultáneamente a todos y cada uno » (IX, 89).

Sin embargo, Cusa no se contenta con solo repetir e ilustrar de manera plástica esta « verdad» de Dios omnividente y omnipresente. A partir del capítulo IV da un giro esencial, haciendo entender que no es Dios el que en realidad se dirige al sujeto, sino que es el sujeto mismo el que tiene que dirigir su mirada y su amor a Él. Los actos de mirar y ser mirado deben ser mutuos. «Para sí mismo » Dios está siempre aquí mientras que «para nosotros » solo está cuando nos dirigimos a Él. Dios está aquí, previa y permanentemente presente, pero es el individuo el que tiene que invocar esta presencia suya, actualizarla cada vez de nuevo (VESEL, 1996): «Tú no abandonas a quien se dirige a ti. Y nadie puede dirigirse a ti si previamente tú no estuvieras presente. Estás presente antes incluso de que yo me dirija a ti $\gg(\mathrm{V}, 77)^{3}$.

Detrás de la imagen que se puede percibir con los ojos sensibles, «carnales », hay que contemplar con los ojos del intelecto la verdadera faz invisible de Dios, representada por este cuadro. «Estoy ante la imagen de tu rostro, Dios mío, que

\footnotetext{
${ }^{1}$ El sentido del título del tratado ya implica esta dicotomía: De visione Dei significa la acción de Dios que mira y a la vez la acción de los hombres que miran a Dios (GonzÁlez, 2009: 26; $c f$. MARINHO NoGUEIRA, 2003).

${ }^{2}$ Todas las citas de la obra De visione Dei son de la edición de Ángel Luis GonZÁLEZ (2009). A continuación se indicará el capítulo y la(s) página(s).

${ }^{3}$ Conviene subrayar que en la concepción cusana esta omnipresencia y omnividencia divina no es considerada como control o advertencia sino como amor: «Y ya que donde está el ojo está el amor, experimento que me amas. [....] Señor, tu ver es amar» (IV, 73).
} 
miro con ojos sensibles; y me esfuerzo en contemplar, con ojos interiores, la verdad que está representada en la pintura » (X, 93). En tanto como forma de todas las formas Dios sobrepasa las determinaciones cualitativas, cuantitativas, espaciales o temporales; es la cara de todas las caras y todas las caras son imagen de la faz divina. La relación entre la imagen divina y la humana es una relación especular, de allí que toda cara que mira la cara divina ve en ella su verdad. En todas las caras se ve «la cara de las caras », pero de manera escondida; puede verse de manera descubierta solo si vamos más allá de todas las caras y entramos en el enigma en el que no hay ni ciencia ni conceptos (VESEL, 1996).

\section{La metáfora de la visión en De visione Dei y El Aleph}

En los cuentos en los que Borges desarrolla la idea del infinito - Las ruinas circulares, La Biblioteca de Babel, El jardín de los senderos que se bifurcan, etc. - esta dimensión interrumpe de repente en lo cotidiano y termina por poner en duda la realidad. En el caso de El Aleph el marco narrativo son las visitas anuales de Borges-protagonista-narrador los días del aniversario de la muerte de Beatriz Viterbo a la casa de la calle Garay en la que siguen viviendo el padre y el primo de la difunta. Sin embargo, lo que a primera vista podría parecer el planteamiento de una historia de amor nostálgico, se desvanece para dejar paso a un suceso fantástico: en un momento dado el protagonista se encuentra delante de un objeto, el Aleph, que le proporciona la visión ilimitada del espacio y del tiempo. El espectáculo encerrado en el Aleph comprende no sólo la geografía del mundo y del universo entero sino además está en todos los tiempos - pasado, presente y futuro. Esta pequeña «esfera tornasolada » que refleja todas las cosas del universo transmite el concepto del infinito que a nivel metafórico corresponde a la « visión absoluta » del Dios cusano.

Una de las características que tienen en común los dos autores, y que puede servir como punto de partida en cuanto a los paralelos entre los dos textos, es la prioridad que le dan ambos al conocimiento humano. Lo hacen cada uno a su manera: el Cusano, como es bien lógico, de acuerdo con el dogma cristiano de la perfección divina, emplea el discurso filosófico-teológico, mientras que Borges se sirve del mismo, pero integrado en el literario, ficcional («falso» diría él). En realidad, con sus típicos giros literarios lo que hace es parodiar el intento de envolver la totalidad en una sola forma representativa. No obstante, es indiscutible que tanto Borges $-\mathrm{y}$ no solo en este cuento sino en prácticamente todos sus escritos - como Cusa se asombran ante el misterio del universo ${ }^{4}$, y ambos destacan la perspectiva humana en el intento por resolver el enigma: Cusa el de Dios y Borges el del universo. Ambos se empeñan por llegar a racionalizarlo, a interpretarlo, a darle una consistencia con ponerlo en palabra; y en esta empresa no quieren admitir la limitación de nuestra percepción y la insuficiencia de la razón humana para explicarlo. «Yo querría saber: ¿Eligió Carlos Argentino ese nombre

\footnotetext{
${ }^{4}$ «La invención de Dios, de la Trinidad, del cielo y del infierno, de los arquetipos platónicos, del panteísmo y de tantas otras construcciones religiosas y filosóficas que sus creadores consideran la justa explicación de la realidad, entusiasman a Borges, que las mira gozando de su magia y de la capacidad imaginativa del hombre » (BARRENECHEA, 1956).
} 
[El Aleph], o lo leyó, aplicado a otro punto donde convergen todos los puntos, en alguno de los textos innumerables que el Aleph de su casa le reveló? » (BORGES, 1974a: 627) ${ }^{5}$, no deja de interrogarse el personaje después del descubrimiento de « ese objeto secreto y conjetural, cuyo nombre usurpan los hombres, pero que ningún hombre ha mirado: el inconcebible universo » (I, 626).

En cuanto al filósofo cristiano, lo que lo eleva por encima de sus contemporáneos no es tanto la tematización de la sabiduría divina sino precisamente lo opuesto - el interés por la posibilidad de la sabiduría humana: «Más que el propio Dios a lo que aspira es al conocimiento sobre Dios » (VESEL, 1996) ${ }^{6}$. No será nuestro propósito indagar en los aspectos teológicos sobre los que versa su texto (la providencia, la trinidad, la gracia divina, la misericordia, Jesús como fusión de la naturaleza divina y humana etc.) sino enfocarnos exclusivamente en el proceso del acercamiento al absoluto. Es precisamente este enfoque original sobre la capacidad del conocimiento humano, este « nuevo modo de entender el conocimiento »(GONZÁLEZ, 2007) lo que le alejó al cardenal alemán de la epistemología escolástica y le valió el título del pensador moderno. Y es este hincapié a la vez lo que lo acerca a la perspectiva borgeana, aunque sus conjeturas no llegan a la altura que alcanza la audacia intelectual del autor argentino. Cusa se detiene en el umbral de la eventualidad (basada en su fe) de alcanzar el conocimiento:

He intentado someterme a este arrebato, para verte a ti que eres invisible [...]. Pero a donde haya llegado, tú lo sabes; yo, en cambio, no lo sé; me basta tu gracia [...] por la que me elevas a la firme esperanza de que llegaré, bajo tu guía, a la fruición de ti (XVII, 122),

mientras que Borges trasgrede esta línea ya que su personaje en el instante culminante del cuento acaba por experimentar el conocimiento total. Y aunque luego pone en duda la autenticidad del Aleph («era un falso Aleph») como si estuviera arrepentido de lo que acaba de ver y tratara de distanciarse de lo ocurrido, este suceso se proyecta más allá de la mera posibilidad, inscribiéndose en el dominio de lo empírico. Como señala STUART (2001) este cuento, al cuestionar los conceptos de totalidad, falsedad y los límites del conocimiento, representa «un lugar de lucha entre el conocimiento de la total revelación y el deseo de mantener la autopreservadora ignorancia ».

Son numerosas las similitudes entre Borges y Cusa en el intento de racionalizar el saber absoluto y el proceso que puede llevar al ser humano hasta el punto de alcanzarlo. Ambas propuestas lo hacen por medio de la misma metáfora, la de la mirada, que les sirve a los dos autores como traductora de conceptos inconcebibles, en este caso la divinidad y el universo respectivamente. Sin un referente real es imposible imaginar lo no existente, por lo cual hay que acercarse a lo absoluto desde lo concreto que es perceptible; solo de este modo lo invisible se hace visible, por lo menos a través de sus señales. Tanto Borges como Cusa, como hemos visto, se proponen llegar a lo infinito a través de la abstracción de lo

\footnotetext{
${ }^{5}$ La cursiva aquí y en adelante es nuestra. Todas las citas del cuento El Aleph son de la edición de Obras completas, I (1974a). A continuación se indican sólo las páginas.

${ }^{6}$ Traducción del esloveno M. Š.
} 
visible, de lo «plástico »: el primero parte de una «esfera tornasolada» y el segundo de un retrato. $\mathrm{Y}$ en ambos casos tanto el sujeto (Borges por un lado y el monje de Tegernsee por el otro) como el objeto (El Aleph y la representación de la faz divina respectivamente) ven y son vistos a la vez: al reflejar/ver todo el universo el Aleph « ve » en sí también al que lo mira, y la faz divina en la pintura « ve » al monje que lo está mirando.

La visión es inmanente al Dios cristiano hasta el punto de identificarse su ver con su ser: «En efecto, Dios [...] es llamado 'theos' porque lo ve todo, » afirma el teólogo (I: 69), o «tu ver es tu ser » (IV: 73), o, más adelante: « Tu vista, Señor, es tu esencia »(IX: 89) ${ }^{7}$. Partiendo de la premisa de que Dios es perfecto, la imagen de este vidente igualmente no puede ser sino perfecta. Cusa formula esta verdad en el título del primer capítulo: «La perfección de esta apariencia se verifica en Dios perfectísimo », lo que quiere decir que la perfección de la visión divina es averada por la propia perfección de Dios. El conocimiento del Dios cristiano es visual, saber es ver y al revés. Él lo ve/sabe todo, en todo momento. Su visión/conocimiento es por lo tanto infinita, absoluta. Esta característica es el punto de partida del tratado que pone de manifiesto a un Deus videns que ve « todas y cada una de las cosas, tanto las ausentes como las presentes, las pasadas como las futuras » (XXII, 136). Esta visión totalizadora contrasta con la ignorancia del ser humano, con su incapacidad de ver y entender a este Dios ${ }^{8}$.

Es pertinente citar aquí el párrafo 30 del capítulo VIII - « La visión de Dios es amar, causar, leer y contener en sí todas las cosas » - para ver la complejidad metafórica con la que Nicolás de Cusa determina la diferencia esencial entre la visión del Creador, infinita (visio absoluta), y la de la creatura, limitada, contraída (visio contracta):

Señor, ves y tienes ojos. Eres ojo, porque tu tener es ser. Por esto contemplas todas las cosas en ti mismo. Si en mí la vista fuera el ojo, como es en ti, mi Dios, entonces yo vería en mí todas las cosas, por ser el ojo como un espejo; y el espejo, por pequeño que sea, puede acoger dentro de sí figurativamente una gran montaña y todas las cosas que existen en la superficie de la montaña. De esa manera están reflejadas en el ojo las especies de todas las cosas. Sin embargo, como nuestra vista no ve por medio de un ojo reflectante más que aquello a lo que se dirige de modo particular, ya que su poder puede determinarse únicamente por el objeto, no ve todas las cosas que se captan en el espejo del ojo. En cambio, tu vista, al ser un ojo o espejo viviente, contempla en sí misma todas las cosas. Más todavía, como tu mirada es la causa de todas las cosas visibles, abarca y contempla todas las cosas en la causa y razón de todo, esto es, en sí misma. Tu ojo, Señor, se dirige a todo sin necesidad de movimiento alguno. Que nuestro ojo se dirija a un objeto sucede porque nuestra vista ve en conformidad con la magnitud del ángulo. El ángulo de tu ojo, oh Dios, no tiene cantidad, sino que es infinito, es un círculo, o más todavía es la esfera infinita, ya que es un ojo dotado de esfericidad y de perfección infinita. Por tanto ve simultáneamente, de modo circular tanto en alto como en bajo, todas las cosas (VIII, 87-88).

\footnotetext{
${ }^{7}$ GonZÁlez (2009: 14) señala que Cusa recurre a menudo a la etimología según la que Theos procedería de dos significados - ver y contemplar y correr o recorrer - que él entrelaza y utiliza indistintamente.

${ }^{8}$ Problema que analiza Cusa también en De docta ignorancia.
} 
Hay toda una serie de términos que despiertan la atención en este pasaje si tenemos en mente el texto borgeano: se repite ocho veces el sintagma «todas las cosas », cuatro veces el sustantivo « espejo » (« ojo como un espejo », « el espejo por pequeño que sea », « el espejo del ojo », «un ojo o espejo viviente »), tres veces el adjetivo «infinito » (el ángulo de tu ojo [...] es infinito«, « [tu ojo ...] es la esfera infinita », « ojo dotado de [...] perfección infinita »), dos veces el concepto de « reflejar» (todas las cosas « están reflejadas en el ojo » y « ojo reflectante ») y dos veces el «ángulo » (« la magnitud del ángulo », « el ángulo de tu ojo »).

La primera mención del Aleph en el cuento de Borges que es proporcionada por Danieri es a la vez una definición de la visión totalizadora que recuerda mucho las formulaciones cusanas. El Aleph es omniabarcante, es un microcosmos que contiene el cosmos entero:

Aclaró que un Aleph es uno de los puntos del espacio que contienen todos los puntos. [...] el lugar donde están, sin confundirse, todos los lugares del orbe, vistos desde todos los ángulos (165-166).

En las dos últimas frases de la parte citada de De visione dei es llamativa la búsqueda de los términos adecuados para determinar la forma de este ojo capaz de ver «todas las cosas »: primero solo su « ángulo [...] es infinito », luego « es un círculo»y, por fin, es una «esfera infinita» que ve - «sin necesidad de movimiento alguno »- todas las cosas en movimiento circulante ( de modo circular tanto en alto como en bajo »), y todo ello « simultáneamente ${ }^{9}$.

La esfericidad, la ilusión del movimiento giratorio y la simultaneidad, son también elementos que completan la primera descripción del Aleph. Al acaecer « este instante gigantesco » en el que el narrador se encuentra en el sótano ante el misterioso objeto que hasta entonces creía ser un producto de la locura de Danieri, lo que ve es una

pequeña esfera tornasolada de casi intolerable fulgor. Al principio la creí giratoria; luego comprendí que ese movimiento era una ilusión producida por los vertiginosos espectáculos que encerraba (169).

Los « vertiginosos espectáculos » hacen que esta primera visión sea colmada de otros matices cada vez más difíciles de entender porque entra en juego el fenómeno tan típicamente borgeano de la multiplicación ad infinitum:

\footnotetext{
${ }^{9}$ La forma esférica supone la perfección infinita y remite a otra característica del ojo divino: es una esfera cuyo centro está en todas partes y su circunferencia en ninguna. El punto desde el que parte la mirada divina es un punto que aparece in infinito en el universo metafísico. Nicolás de Cusa fue el primero en discutir esta conjetura en el tratado De docta ignorancia (cf. VESEL, 1996: 147-148). Borges retoma la misma formulación en El Aleph (« [...] y Alanus de Insulis, [habla] de una esfera cuyo centro está en todas partes y la circunferencia en ninguna »(625)), y le dedica además uno de sus ensayos paradigmáticos, La esfera de Pascal, sin embargo, como ya hemos destacado, sin referirse al teólogo. En cuanto a las posibles razones de la omisión de la referencia a Nicolás de Cusa en La esfera de Pascal cf. DANVERS (2006: 290-291) y PALMA (2007).
} 
En ese instante gigantesco, he visto millones de actos deleitables o atroces; ninguno me asombró como el hecho de que todos ocuparan el mismo punto, sin superposición y sin transparencia. [...] Cada cosa (la luna del espejo, digamos) era infinitas cosas, porque yo claramente la veía desde todos los puntos del universo (625).

Mientras que Cusa, como hemos observado, se detiene en el término genérico para la totalidad («todas las cosas »), Borges trata de enumerar los más diversos puntos del mundo, de gente, objetos, conceptos etc., que en « ese instante gigantesco » cupieron en aquella « esfera tornasolada ». Sin embargo, al querer dar fe de las cosas y actos que encierra el Aleph, el narrador se encuentra con un problema que le provoca infinita frustración: la conciencia de su incapacidad de transmitir esta experiencia de la misma manera que la ha vivido. Se trata de la simultaneidad por un lado y la sucesividad por el otro - dos propiedades opuestas, relativas a la visión y a la narración respectivamente. Lo que capta la mirada es simultáneo, mientras que la narración está condicionada por el lenguaje, que es sucesivo por defecto. Así expresa el narrador su exasperación al no poder conciliar estas dos cualidades:

Arribo, ahora, al inefable centro de mi relato, empieza, aquí, mi desesperación de escritor. [...] el problema central es irresoluble: la enumeración, siquiera parcial, de un conjunto infinito. [...] Lo que vieron mis ojos fue simultáneo, lo que transcribiré sucesivo, porque el lenguaje lo es. Algo, sin embargo, recogeré (625).

A nivel metafísico esta limitación del lenguaje viene a sugerir que el ser humano es capaz de acercarse al infinito mediante imágenes parciales, pero que nunca podrá alcanzarlo del todo. Jonathan STUART en su estudio sobre Borges y el simulacro (2001: 366) presenta este intento de Borges como tarea paradójica presentar (narrar o escribir) lo infinito en un lenguaje limitado y limitador. De hecho, tanto el Aleph borgeano como la visión divina cusana están más allá del lenguaje como tal, más allá de todo concepto y, por ende, inconceptualizables.

En su intento desesperado y de entrada condenado al fracaso, Borges consigue ensartar una sucesión de alrededor de cuarenta elementos, cada uno introducido por el verbo ver en primera persona del pasado simple, como en una suerte de conjuro: «Vi el populoso mar, vi el alba y la tarde, vi las muchedumbres de América ... ». En este desfile febril y sofocante destacan los espejos («vi todos los espejos del planeta »), desiertos («vi convexos desiertos ecuatoriales y cada uno de sus granos de arena »), y libros («vi un ejemplar de la primera versión inglesa de Plinio [...], vi a un tiempo cada letra de cada página $\left.{ }^{10} \gg\right)$, que son de por sí, a su vez, para Borges metáforas del infinito universo.

Aparecen «todos los espejos del planeta» (sin que ninguno lo refleje) y aparecen los espejos enfrentados «su expresión más típica de la pluralidad de los límites » (BARRENECHEA, 1956): «vi [...] un globo terráqueo entre dos espejos que lo multiplican sin fin [...] vi el Aleph, desde todos los puntos, vi en el Aleph la tierra $($ (625-626). Las multiplicaciones interminables acaban por arrojarnos al

\footnotetext{
${ }^{10}$ Concluye Borges esta alusión con el tierno recuerdo infantil entre paréntesis: « de chico yo solía maravillarme de que las letras de un volumen cerrado no se mezclaran y perdieran en el decurso de la noche » que anuncia de una manera sugestiva su concepción del universo y de la literatura.
} 
abismo en el que se borran definitivamente las fronteras entre la tierra y el universo, entre la imagen y su reflejo, entre el emisor y el receptor, entre los personajes del cuento y el lector. Este momento culminante del cuento revela toda la complejidad de las especulaciones borgeanas en cuanto a su particular concepción del universo que concuerdan con la idea del Creador transcendente que « viendo las cosas, se ve a sí mismo; y viéndose a sí mismo, ve las cosas creadas » (GONZÁLEZ, 2009: 16). Puesto que tanto el Aleph como el ojo divino reflejan todas las cosas, se reflejan/ven también a sí mismos. Borges se ve a sí mismo dentro del Aleph, ve incluso el interior de su propio cuerpo («vi mi cara y mis vísceras », « vi la circulación de mi oscura sangre »), y ve a los demás que se están mirando en él (« vi interminables ojos escrutándose en mí como en un espejo »), lo que supone que se ve también a sí mismo reflejándose a sí mismo. Esta carrera desrealizadora termina por tragar también al lector que está leyendo el cuento (« vi tu cara »), es decir, a nosotros, que al igual que los demás elementos nos proyectamos y reflejamos mutuamente ad infinitum. STUART (2001) resume esta mise en abîme de la siguiente manera: el Aleph simultáneamente refleja el original (el universo), encubre su originalidad, encubre la ausencia de su realidad y, además, se simula a sí mismo. Es decir, que ya no representa la totalidad del universo sino el vertiginoso universo en abîme o su propio simulacro ${ }^{11}$.

La evocación de la dicotomía entre lo simultáneo (o total) y lo sucesivo proporciona otro paralelo sorprendente con las formulaciones cusanas. No solo que el cardenal también contraponga estos dos conceptos sino que lo hace además con una metáfora borgeana por excelencia - el libro:

Cuando abro un libro, para leerlo, veo confusamente la página entera. Y si quiero distinguir cada una de las letras, las sílabas y las palabras, me es necesario examinar una por una individual y sucesivamente: no puedo leer más que una letra tras otra sucesivamente, una palabra después de otra, y un párrafo tras otro. Pero tú, Señor, ves toda la página simultáneamente, y la lees sin intervalo de tiempo. [...] tú lees todas las cosas por encima del tiempo y simultáneamente; tu ver es tu leer (VIII, 87).

Los dos autores parten de la diferencia entre la simultaneidad de la visión y la sucesividad del lenguaje como narración y, consecuentemente, como escritura y lectura. Puesto que la visión divina es total, es capaz de compehender/leer en un instante todas las letras, las sílabas, las palabras, los pasajes de una página del libro, cada uno por separado y todos juntos a la vez, mientras que el ser humano solo puede «consumir » este encadenamiento de elementos avanzando paso a paso por cada uno de ellos ${ }^{12}$.

\footnotetext{
${ }^{11}$ Esta perspectiva abismal que deja de distinguir entre lo real y su representación o ilusión, entre el original y la copia, entre lo metafísico y lo físico es la piedra de toque de la teoría del posmodernismo ( $c f$. STUART, 2001).

${ }^{12}$ Cusa vuelve sobre el tema de la sucesión en el capítulo XI: «Cómo pueda verse en Dios una sucesión sin sucesión ».
} 


\section{Conclusión}

Los dos textos, cada uno en su cosmovisión, demuestran que el ser humano por mucho que se esfuerce puede solo acercarse al infinito mediante imágenes parciales (y sucesivas) - sin alcanzarlo nunca. Pero al mismo tiempo demuestran que esta imposibilidad de penetrar el esquema sea divino o agnóstico del universo no puede, sin embargo, disuadir al ser humano de plantear sus propios esquemas, aunque nos conste que éstos son provisorios.

Nicolás de Cusa, en su condición de filósofo creyente, lo construye sobre los postulados de la doctrina cristiana, es decir, que su «teoría de la mirada » implica la existencia de un vidente universal, un ente absoluto al que le es dada la calidad de omnividente. De allí que su propuesta puede ser, hasta cierto punto, concebible. La imagen ilusionista de Jesucristo remite a un referente «real ». La cosmovisión borgeana, sin embargo, no proporciona ningún soporte tangible. La única creencia de Borges se alimenta en los postulados del conocimiento humano, no hay otra instancia por encima de él, por lo cual, su teoría de la visión total - al no poder ser comprehendida por la mente humana - nos lleva a la más absoluta abstracción. Pero en este punto la abstracción ya no se inscribe en el dominio filosófico sino literario. El discurso de Borges, aunque colmado de ideas filosóficas, no debe ser entendido como filosófico - las enunciaciones literarias no pueden ser adoptadas como argumentos lógicos. La particularidad de la literatura es que puede transmitir pensamientos «filosóficos», pero sirviéndose de otros recursos a parte de la filosofía. Aunque las dos pueden utilizar procedimientos retóricos similares (en nuestro caso la metáfora), el significado de este uso en la filosofía es sometido a la argumentación que lleva a la validez de determinado pensamiento y no a la valoración estética como es el caso en la literatura. Lo que en Borges a primera vista parecen silogismos son, en realidad, enunciaciones literarias, metafóricas, que esto sí, no solo ayudan a representar las ideas filosóficas sino que además muchas veces las fomentan. Con todo ello El Aleph es uno de textos más emblemáticos con los que Borges, como sostiene VIRK (2000) «'devuelve' a la filosofía lo que había recibido (también) de ella ». 


\section{BIBLIOGRAFÍA}

BARRENECHEA Ana María (1956), El infinito en la obra de Jorge Luis Borges, Nueva Revista de Filología Hispánica, 10, 1, pp. 13-35.

Borges Jorge Luis (1974a), Obras completas, I, Buenos Aires-Madrid, Emecé Editores-Aianza Editorial.

BORGES Jorge Luis (1974b), Obras completas, II, Buenos Aires-Madrid, Emecé Editores-Alianza Editorial.

Cavallín Calanche Claudia (2008), Posibilidades de la metáfora en Borges, Atenea, 498, pp. 45-54.

Certeau Michel de (1984), Nicolas de Cues: Le secret d'un regard, Traverses, 30-31, pp. 70-84. Trad. eslovena VESEL, Matjaž (1996), Nikolaj Kuzanski: Skrivnost pogleda, Filozofski vestnik I Acta Philosophica, XVII/1, Ljubljana, Filozofski inštitut ZRC SAZU, pp. 153-174.

CUSANUS Nicolaus, Obra completa en latín, alemán e inglés. Accesible en: Cusanus Portal, http://www.cusanus-portal.de [30. 9. 2014].

CusA Nicolás de (2009), La visión de Dios, trad. esp. GONZÁLEZ Ángel Luis, Pamplona, Eunsa.

D’AMICO Claudia (2012), Visión absoluta y visión de lo absoluto en Nicolás de Cusa, Mirabilia, 14, pp. 228-241.

DANVERS John (2006), Picturing Mind: Paradox, Indeterminacy and Consciousness in Art \& Poetry, Amsterdam-Nueva York, Editions Rodopi.

GONZÁLEZ Ángel Luis (1995), Ver e imagen del ver: acotaciones sobre el capítulo XV del De Visione Dei de Nicolás de Cusa, Anuario Filosófico, 28, pp. 627648.

GonZÁlez Ángel Luis (2007), La doctrina de Nicolás de Cusa sobre la mente. Hacia una nueva gnoseología, Studia Philologica Valentina, 10, n.s. 7, pp. 124.

GONZÁLEZ Ángel Luis (2009), La articulación de la transcendencia y de la inmanencia del absoluto en De visione Dei de Nicolás de Cusa, en: Nicolás de Cusa, La visión de Dios, Pamplona, Eunsa, pp. 11-60.

KADIR Djelal (2011), Of Learned Ignorance, en: Memos from the Besieged City: Lifelines for Cultural Sustainability, Stanford, Stanford University Press.

KUZANSKI Nikolaj (1997), O božjem pogledu [De visiones Dei], trad. eslovena GEISTER Ksenja, Ljubljana, Družina, coll. Tretji dan.

MagnavaCCA Silvia (2005), Ecos cusanos en J. L. Borges, en: MACHETTA Jorge M. y D’AMICO, Claudia (eds.), El problema del conocimiento en Nicolás de Cusa: genealogía y proyección, Buenos Aires, Editorial Biblos, pp. 365-676.

MagnavacCA Silvia (2007), Neoplatonismo medieval en Borges, en: Anales del Seminario de Historia de la Filosofía, 24, pp. 67-83. Accesible en: http://www.redalyc.org/pdf/3611/361133108011.pdf [30. 9. 2014].

MagnaVACCA Silvia (2009): Filósofos medievales en la obra de Borges, San Martín (Bs. As.), Miño y Dávila.

MARINHO NoGUEIRA (2003), Maria Simone: La metáfora del mirar en Nicolás de Cusa, Anales del Seminario de Historia de la Filosofía, 20, pp. 69-78. 
PALMA Alejandro (2007), Borges, Bohm, Bruno: vasos comunicantes entre tres genios, Letras libres, mayo 2007. Accesible en: http://www.letraslibres.com/revista/convivio/borges-bohm-bruno $\left[\begin{array}{ll}30 . & 9\end{array}\right.$ 2014].

StUART BOULTER Jonathan (2001), Partial glimpses of infinite: Borges and the simulacrum, Hispanic review, 2, pp. 355-377.

ŠKAMPERLE Igor (1997), Odsev neskončnega v končnem. Filozofije Nikolaja Kuzanskega, en: Nikolaj Kuzanski, O božjem pogledu, Ljubljana, Družina, coll. Tretji dan, pp. 91-108.

VESEl Matjaž (1996), Božji pogled, Filozofski vestnik I, Acta Philosophica, XVII/1, Filozofski inštitut ZRC SAZU, Ljubljana, pp. 137-152.

URŠIČ Marko, ŠKAMPERLE Igor (eds.) (2001), Nikolaj Kuzanski, Poligrafi, VI/2324, Ljubljana, Nova revija.

VIRK Tomo (2000), Borges v kontekstu filozofije in teorije, en: KALENIĆ RAMŠAK, Branka (ed.), Actas de las Jornadas internacionales sobre Jorge Luis Borges, Ljubljana 1999, Ljubljana, Znanstveni Inštutut Filozofske fakultete, pp. 147-152.

WoscoBoiniK Julio (1996), El alma de «El Aleph». Nuevos aportes a la indagación psicoanalítica de la obra de Jorge Luis Borges, Buenos Aires, Grupo Editor Latinoamericano. Accesible en: http://www.borges.pitt.edu/bsol/jw0.php [30. 9. 2014]. 